\title{
Modeled exposure to tetrachloroethylene- contaminated drinking water and the occurrence of birth defects: a case-control study from Massachusetts and Rhode Island
}

\author{
Ann Aschengrau ${ }^{1 *}$ (D), Lisa G. Gallagher ${ }^{1}$, Michael Winter ${ }^{2}$, Lindsey Butler ${ }^{3}$, M. Patricia Fabian ${ }^{3}$ and
} Veronica M. Vieira ${ }^{4}$

\begin{abstract}
Background: Residents of Massachusetts and Rhode Island were exposed to tetrachloroethylene-contaminated drinking water from 1968 through the early 1990s when it leached from the vinyl lining of asbestos cement water distribution pipes. While occupational exposure to solvents during pregnancy has consistently been linked to an increased risk of certain birth defects, mixed results have been observed for environmental sources of exposure, including contaminated drinking water. The present case-control study was undertaken to examine further the association between prenatal exposure to tetrachloroethylene-contaminated drinking water and the risk of central nervous system defects, oral clefts and hypospadias.

Methods: Cases were comprised of live- and stillborn infants delivered between 1968 and 1995 to mothers who resided in 28 Massachusetts and Rhode Island cities and towns with some PCE-contaminated water supplies. Infants with central nervous system defects $(N=268)$, oral clefts $(N=112)$ and hypospadias $(N=94)$ were included. Controls were randomly selected live-born, non-malformed infants who were delivered during the same period and geographic area as cases $(N=771)$. Vital records and self-administered questionnaires were used to gather identifying information, birth defect diagnoses, and other relevant data. PCE exposure during the first trimester was estimated using water distribution system modeling software that incorporated a leaching and transport model. Prenatal PCE exposure was dichotomized as "high" or "low" exposure at the level corresponding to an estimated average concentration of $40 \mathrm{\mu g} /$ $L$, the criterion for remediation when PCE contamination was discovered in 1980.
\end{abstract}

Results: Mothers with "high" levels of exposure to PCE-contaminated drinking water during the first trimester (> $40 \mu \mathrm{g} /$ L) had increased odds of having a child with spina bifida (OR: 2.0,95\% Cl: 0.8-5.4), cleft lip with or without cleft palate (OR: 3.8, 95\% Cl: 1.2-12.3) and hypospadias (OR: 2.1, 95\% Cl:0.5-8.3). No increases in the odds of other defects were observed in relation to "high" exposure levels.

\footnotetext{
* Correspondence: aaschen@bu.edu

${ }^{1}$ Department of Epidemiology, Boston University School of Public Health, 715

Albany Street, Talbot 3 East, Boston, MA 02118, USA

Full list of author information is available at the end of the article
}

(c) The Author(s). 2018 Open Access This article is distributed under the terms of the Creative Commons Attribution 4.0 International License (http://creativecommons.org/licenses/by/4.0/), which permits unrestricted use, distribution, and reproduction in any medium, provided you give appropriate credit to the original author(s) and the source, provide a link to the Creative Commons license, and indicate if changes were made. The Creative Commons Public Domain Dedication waiver (http://creativecommons.org/publicdomain/zero/1.0/) applies to the data made available in this article, unless otherwise stated. 


\begin{abstract}
(Continued from previous page)
Conclusions: The results of the present study suggest that mothers with "high" PCE exposure levels during the first trimester have increased odds of having a child with spina bifida, cleft lip with or without cleft palate, and hypospadias. These findings support several prior studies that observed an increased risk of selected birth defects following prenatal exposure to solvents in occupational and environmental settings. Even though PCE contamination from vinyl lined pipes was remediated many years ago, it remains a widespread contaminant across the U.S and so environmental regulations must be guided by a precautionary perspective that safeguards pregnant women and their offspring.
\end{abstract}

Keywords: Tetrachloroethylene, Drinking water, Birth defects

\section{Background}

Tetrachloroethylene (PCE) is a commercially important solvent used in dry cleaning, textile processing, and metal degreasing [1]. Because most of its use occurs in poorly controlled workplaces such as dry cleaning businesses and garages, PCE is a frequent contaminant of public drinking water supplies in the United States [2,3]. The most recent sampling survey from the U.S. Geological Survey found PCE in $7 \%$ of surface water samples and $24 \%$ of groundwater samples [3].

While improper waste disposal is the typical source of PCE-contaminated drinking water, the public drinking water supplies in New England were affected when PCE leached from the vinyl lining (VL) of asbestos cement (AC) water distribution pipes. The liner, which was applied to the interior of the pipe in a slurry of vinyl toluene resin and PCE, had been introduced in 1968 in response to complaints about water's taste and odor [4]. Pipes were dried for $48 \mathrm{~h}$ before shipping assuming that most of the PCE would evaporate by the time the pipes were installed [5]. Yet, more than a decade lapsed before it was discovered that large quantities of PCE remained in the liner and leached into the public drinking water supplies.

Officials in Massachusetts (MA) and Rhode Island (RI) determined that approximately 750 miles of VLAC pipes had been installed in about 100 cities and towns in the two states [4]. Because the lined pipes were used to replace existing pipe and extend the water system as the population grew, neighboring streets had different contaminant levels.

Levels in MA water monitoring samples taken in 1980 ranged from 1.5 to $80 \mu \mathrm{g} / \mathrm{l}$ in medium and high flow locations and 1600 to $7750 \mu \mathrm{g} / \mathrm{l}$ in low flow locations [5]. RI samples from eleven systems had levels that exceeded the 1980 EPA suggested no adverse response level (SNARL) of $40 \mu \mathrm{g} / \mathrm{L}$ [6]. Remediation to bring water levels below the SNARL was subsequently initiated by bleeding and flushing the pipes [5]. The maximum contaminant level is currently $5 \mu \mathrm{g} / \mathrm{l}$ and reported levels in MA and RI are now below this level [7, 8].

PCE's neurotoxic and carcinogenic effects have been well-established [1,9]. There is also evidence of adverse effects on birth outcomes, including congenital anomalies.
Animal experiments suggest that prenatal exposure to PCE and trichloroethylene (TCE) increase the risk of anomalies (e.g., [10, 11]). Several epidemiological studies have also reported associations between occupational exposure to organic solvents during pregnancy and congenital anomalies [12-19]; however, the literature examining women with community exposure to contaminated air and drinking water has conflicting findings [20-28].

Our prior retrospective cohort study in Cape Cod, MA found that women with any prenatal PCE exposure had infants with a 3.1-fold increased risk of central nervous system defects (95\% CI: 0.9-11.0), a 3.5-fold increased risk of neural tube defects (95\% CI: $0.8-14.0$ ), a 3.2-fold increased risk of oral clefts (95\% CI: 0.7-15.0), and a 1.4-fold increased risk of hypospadias $(95 \% \mathrm{CI}$ : 0.4-5.4) [20]. Because these findings were based on a small number of cases identified via maternal reports, we undertook present case-control study to examine further the association between PCE-contaminated drinking water and the risk of birth defects with a larger number of cases identified through vital records.

\section{Methods}

\section{Selection of study population}

Cases were comprised of live- and stillborn infants who were delivered from 1968 through 1995 to residents of 24 MA and four RI cities and towns with some VLAC water distribution pipes. Approximately 480 miles of VLAC pipes were installed in these towns, representing approximately $63 \%$ of the VLAC pipes in the two states. The remaining RI and MA towns with VLAC pipes were excluded from the present study because they had few VLAC pipes, lacked documentation on the locations and dates of VLAC pipe installation, and/or small resident populations. Available water sampling data indicated that PCE contamination persisted in public water supplies of selected towns through the 1990s because the target level for remediation was $40 \mu \mathrm{g} / \mathrm{L}$ [7].

Cases were identified by abstracting birth defect diagnoses from livebirth, fetal death, and death certificate records $(N=479)$. Based on associations observed in our prior cohort study [20], infants with the following defects were selected: central nervous system defects 
(CNS) (including anencephaly, spina bifida with or without hydrocephalus, encephalocele, hydrocephalus alone, microcephaly and other CNS defects), oral clefts (cleft lip with and without cleft palate and cleft palate alone), and hypospadias. Cases with more than one birth defect were eligible for inclusion; however, those with recognized syndromes were excluded. Prenatal testing followed by elective termination of affected pregnancies was uncommon during the case ascertainment period [29, 30].

Controls were randomly selected from livebirth records of non-malformed infants born during the same period to residents of the same geographic area as the cases. The control selection process was stratified by state and birth year so that the number of controls selected from MA and RI was proportional to their number of births over the ascertainment period (45\% from RI and 55\% from MA). A total of 800 controls were targeted for selection; 794 remained after excluding duplicate subjects.

\section{Questionnaire and vital record data collection}

Paper copies of livebirth, fetal death and death certificates and computerized vital record data were abstracted to obtain parent's and infant's names; maternal address at delivery; infant's date of birth; maternal age, race, and educational level; paternal age and educational level; maternal pregnancy history; date of last menstrual period; prenatal care information and birth defect diagnoses.

Mothers were subsequently traced and sent self-administered questionnaires. Overall, $4.2 \%$ of case mothers $(N=$ $20)$ and $7.2 \%$ of control mothers $(N=57)$ were found to be deceased. We successfully located 87.4 and $88.3 \%$ of living case $(N=401)$ and control mothers $(N=651)$, respectively, and, of these, $38.6 \%$ of case mothers $(N=155)$ and $31.8 \%$ of control mothers $(N=207)$ returned the questionnaire after two mail and one telephone reminder. The purpose of the questionnaire was to identify mothers who moved during pregnancy and augment vital records data on birth defect diagnoses and confounding variables.

When we compared the demographic characteristics of questionnaire respondents and non-respondents, we found that the two groups were similar with respect to PCE exposure status $(68.5 \%$ of case respondents versus $68.0 \%$ of case non-respondents and $66.2 \%$ of control respondents versus $70.7 \%$ of control non-respondents) and delivery year (e.g., $28.9 \%$ of case respondents versus $26.7 \%$ of case non-respondents and $37.4 \%$ of control respondents versus $37.7 \%$ of control non-respondents delivered during 1968-1978). While respondents were more likely to reside in Massachusetts (77.2\% of case respondents versus $66.8 \%$ of case non-respondents and $72.8 \%$ of control respondents versus $51.0 \%$ of control non-respondents), be older at delivery (median age was 29.0 for case respondents versus 26.7 for case non-respondents and 28.3 for control respondents versus 26.6 for control non-respondents), and begin prenatal care in the first trimester $(93.9 \%$ of case respondents versus $85.3 \%$ of case non-respondents and $90.8 \%$ of control respondents versus $86.3 \%$ of control non-respondents), these differences were present for both case and control mothers who returned our study questionnaire.

\section{Geocoding of residential addresses}

Residential addresses at birth recorded in vital records were geocoded to a latitude and longitude using ArcGIS (10.0, ESRI, Redlands, CA). First trimester addresses of questionnaire respondents who moved during pregnancy were also geocoded ( $N=33$ cases and 33 controls). Whenever possible, each address was assigned to a parcel of land. Addresses that could not be geocoded to a parcel were geocoded to the closest parcel address by street number. If a street number was unavailable, the address was geocoded to the middle of the street when the street was less than a mile long or to the intersection of the address with the cross-street when the street was a mile or longer. Overall $98.7 \%$ of the addresses were successfully geocoded. All geocoding was conducted without knowledge of case-control status.

\section{PCE exposure assessment}

Because historical water sampling data for PCE was scant, we estimated each subject's prenatal exposure used a leaching and transport model. The model was developed for our research by Webler and Brown [31, 32] to estimate the mass of PCE entering the drinking water using the starting quantity of $\mathrm{PCE}$ in the pipe liner, the pipe's age, the leaching rate of PCE from the liner into the water, and the water flow rate through the pipe. The initial amount of PCE in the liner was based on the pipe dimensions and information from the manufacturer on the application of the liner. The leaching rate of PCE was determined in experiments by Demond [5].

We incorporated the Webler Brown algorithm into the open source code of EPANET, water distribution system modeling software created by the US EPA [33]. Initially designed to investigate water quality problems, EPANET has been used in several epidemiological studies investigating adverse health effects of drinking water contaminants (e.g. [34]). The combined modeling approach integrated pipe schematics, water use, and PCE transport to determine the water flow rate and direction and the amount of PCE at points of consumption throughout the distribution system.

GIS maps of geocoded residences and the water distribution systems were used to construct a graphic for each town depicting the locations and characteristics of the pipes (e.g. VLAC or not) and consumption points. We assigned each mother's residence to the closest consumption point on the distribution system. The model simulation estimated 
the average mass of PCE in grams delivered to each subject's residence during the calendar year when the first trimester ended. We estimated the annual exposure because we did not have data on the month of move-in or VLAC pipe installation. Average monthly exposure was obtained by dividing annual exposures by 12 . Questionnaire respondents who report using a private well for their prenatal water supply $(N=21)$ were considered unexposed.

\section{Data analysis}

The strength of the association between PCE exposure and each birth defect was estimated with odds ratios (OR) and statistical stability was evaluated with 95\% confidence intervals. The following defect groups were examined: any central nervous system defect, any neural tube defect, any anencephaly, any spina bifida (with and without hydrocephalus), any other CNS defects, any oral cleft, any cleft lip (with or without cleft palate), cleft palate alone, and hypospadias. Cases with more than one of these defects contributed to each subgroup. Analyses of hypospadias were limited to male cases and controls. ORs were calculated only if there were at least three exposed cases and three exposed controls.

Analyses first compared mothers who were ever exposed to PCE-contaminated drinking water during the calendar year the first trimester ended to unexposed mothers. We focused on exposure during the first trimester because the structural defects under study form during this period [35]. Next, we dichotomized PCE exposure at $1.136 \mathrm{~g}$, the level corresponding to an average monthly drinking water concentration of $40 \mu \mathrm{g} / \mathrm{L}$ during the calendar year that the first trimester ended. This concentration was the criterion for remediation when PCE contamination was discovered in 1980. Levels above $40 \mu \mathrm{g} / \mathrm{L}$ were designated as "high." Each set of analyses was repeated after (1) incorporating exposure levels at the first trimester address for questionnaire respondents who moved during pregnancy, (2) excluding cases and controls with a family history of defects, (3) excluding cases with multiple defects, and (4) excluding cases included in our prior cohort study $(N=10)$.

Logistic regression models estimated ORs while controlling for confounding variables. We selected potential confounders from those available in the vital records and self-administered questionnaires based on a literature review and construction of directed acyclic graphs. Multiple imputation was used to obtain values of potential confounders with missing data. The amount of missing data ranged from $0 \%$ (state of residence and delivery year) to $72.5 \%$ (maternal alcoholic beverage consumption). Variables with a high proportion of missing data came solely from the self-administered questionnaires. Twenty imputed data sets were generated using the fully conditional specification (FCS) multiple imputation method based on 27 variables. Point and variance estimates from the imputed data sets were subsequently combined and used in adjusted analyses.

Initial adjusted models controlled for one potential confounder at a time. Controlling for delivery year had the greatest impact on the crude associations and so it was included in all multivariate models. We also decided to include state in all multivariable models to account for variations in case ascertainment between the two states. Additional variables that changed the crude association between PCE exposure and each type of birth defect by $>=10 \%$ were also included in the final models; these included maternal alcoholic beverage consumption in the oral cleft analyses and maternal race in the hypospadias analyses.

\section{Results}

The final analysis was based on 268 cases with CNS malformations (including 151 neural tube defects and 117 other CNS defects), 112 cases with oral clefts (including 59 with cleft lip with or without cleft palate and 53 with cleft palate alone), 94 cases with hypospadias, and 771 controls. These numbers include 10 cases identified through the maternal questionnaire: 7 cases of hypospadias, 1 case of spina bifida and 2 cases of cleft lip with cleft palate. In addition, these numbers exclude 5 cases and 11 controls whose residential information was insufficient for geocoding, 12 controls whose questionnaire data indicated the presence of a congenital anomaly (that was not recorded in state records), and 12 cases whose questionnaire data indicated that the defect was part of a syndrome (also omitted from state records).

Overall, $68.3 \%$ of CNS cases, $72.3 \%$ of oral cleft cases, $61.7 \%$ of hypospadias cases and $67.8 \%$ of control mothers had some PCE exposure during the first trimester. The exposure distributions of cases and controls spanned several orders of magnitude (Table 1). There were no discernable trends in the exposure distribution of cases versus controls, except at the upper end of the distribution where higher exposure levels were observed among cases.

Both case and control mothers were predominantly white but, depending on the case group, differed on many other demographic and behavioral characteristics, such as state of birth, delivery year, maternal educational level and prenatal cigarette smoking (Table 2).

Any PCE exposure during the first trimester was not associated with meaningful increases in the adjusted odds of all CNS defects combined, neural tube defects, anencephaly, spina bifida, other CNS defect or hypospadias (Table 3). In contrast, any first trimester PCE exposure was associated with a 2.1-fold increase in the adjusted odds of cleft lip with or without cleft palate (95\% CI: $1.1-4.0)$ that rose to 3.8 for prenatal PCE exposure levels above $40 \mu \mathrm{g} / \mathrm{L}$ (95\% CI: $1.2-12.3$ ) ( $p$ value 
Table 1 Distribution of Average Monthly PCE Exposure (g) During Year First Trimester Ended Among All Exposed Case and Control Mothers

\begin{tabular}{lll}
\hline & $\begin{array}{l}\text { Exposed } \\
\text { Case Mothers }\end{array}$ & $\begin{array}{l}\text { Exposed } \\
\text { Control Mothers }\end{array}$ \\
\hline Minimum & $5.2 \times 10^{-7}$ & $2.1 \times 10^{-8}$ \\
5th Percentile & $2.1 \times 10^{-5}$ & $2.2 \times 10^{-5}$ \\
10th Percentile & $7.7 \times 10^{-5}$ & $5.4 \times 10^{-5}$ \\
25th Percentile & $4.4 \times 10^{-4}$ & $6.8 \times 10^{-4}$ \\
Median & $3.4 \times 10^{-3}$ & $5.9 \times 10^{-3}$ \\
75th Percentile & $3.9 \times 10^{-2}$ & $5.6 \times 10^{-2}$ \\
90th Percentile & $5.0 \times 10^{-1}$ & $4.3 \times 10^{-1}$ \\
95th Percentile & 1.8 & 1.2 \\
Maximum & 24.8 & 81.81 \\
\hline
\end{tabular}

for trend 0.13). "High" PCE exposure levels were also associated with increases in the adjusted odds of spina bifida with and without hydrocephalus (OR: 2.0, 95\% CI: $0.8-5.4$ ) and hypospadias (OR: 2.1, 95\% CI: 0.5-8.3). No increases in the odds of other CNS defects were observed in relation to "high" PCE exposure levels. Only one case of cleft palate alone was exposed to "high" PCE exposure levels and so we did not estimate its associated odds ratio; any PCE exposure was associated with a 1.4-fold increase in the adjusted odds of cleft palate alone (95\% CI: 0.7-2.7).

No meaningful changes in these results were observed when the analysis incorporated exposure levels at the first trimester address for questionnaire respondents who moved during pregnancy or excluded cases and controls with a family history of defects, cases with multiple defects, or cases in our prior cohort study (data not shown).

\section{Discussion}

The results of the present study suggest that pregnant women exposed to "high" levels of PCE-contaminated drinking water during the first trimester have an increased odds of spina bifida, cleft lip with or without cleft palate and hypospadias. No evidence of increases in the odds of other defects were observed in relation to "high" exposure levels.

Several limitations should be considered when interpreting these results. First, these findings are statistically unstable and have wide confidence intervals because a small number of mothers were exposed to PCE levels above the remediation cut point. Second, even though results from a prior validation study indicate good correlation between our modeled exposure estimates and PCE concentrations in historical water samples from Cape Cod (Spearman correlation coefficient $(\rho)=0.65, p<0.00010$ [36], non-differential exposure misclassification stemming from our model-based exposure estimates likely attenuated the observed associations. In addition, our leaching and transport model did not estimate personal exposure levels but rather the mass of PCE delivered to the home. Behavioral data on prenatal water consumption and bathing habits during 1969-1995 were available only for questionnaire respondents and considered poor quality because of the long recall period. Thus, it was not incorporated into our analysis.

Still another limitation arose from using vital records to identify birth defect cases and non-malformed controls because this source of information was likely to suffer from mis-reporting and under-reporting. Direct evidence for these inaccuracies comes from the questionnaire data where mothers reported 12 syndromes that had been recorded as single defects in vital records and 22 defect diagnoses that were not recorded in vital records. Indirect evidence comes from birth defects surveillance data in Massachusetts and Rhode Island that suggest the number of cases identified (with the possible exception of anencephaly) was lower than expected when multiple sources of case ascertainment are used $[37,38]$. However, even though there was a great deal of publicity when the contamination was discovered in 1980, possible carcinogenic effects were the focus of concern in newspaper reports (e.g., [39]), and so there is no reason to believe that recording of defects in vital records was related to PCE exposure. There is also no reason to believe that reporting of defects on the questionnaire was related to PCE exposure since only $2 \%$ of exposed mothers thought that their drinking water was contaminated with PCE. Thus, these errors were likely non-differential thereby biasing the results towards the null.

Because VLAC pipes were used to replace existing pipes and expand the distribution system in response to the growing population, the geographic pattern of contamination was irregular. In fact, depending on the direction of water flow, neighboring homes could have very different exposure levels. Thus, despite several different characteristics among cases and controls, little confounding was observed in the analysis likely from the lack of associations between PCE exposure and potential confounders. Multiple imputation procedures were used fill in missing values on confounders. While they are considered the most valid approach for handing this problem [40], we cannot rule out the possibility that residual confounding affected the results.

Selection bias was unlikely because we were unaware of the exposure status when we selected cases and controls for study. Despite the low questionnaire response rate and the numerous demographic differences between respondents and non-respondents, these differences were present for both cases and controls and so were unlikely sources of bias. Moreover, analyses were conducted on the entire sample, irrespective of respondent status. 
Table 2 Distribution of selected characteristics of cases and controls

\begin{tabular}{|c|c|c|c|c|c|c|c|c|}
\hline \multirow[t]{2}{*}{ Characteristic } & \multicolumn{2}{|c|}{ CNS Cases $(N=268)$} & \multicolumn{2}{|c|}{ Oral Clef Cases $(N=112)$} & \multicolumn{2}{|c|}{ Hypospadias Cases $(N=94)$} & \multicolumn{2}{|c|}{ All Controls $(N=771)$} \\
\hline & $n$ & $\%$ & $n$ & $\%$ & $\mathrm{n}$ & $\%$ & $\mathrm{n}$ & $\%$ \\
\hline \multicolumn{9}{|l|}{ Maternal residence at delivery } \\
\hline Massachusetts & 167 & 62.3 & 85 & 75.9 & 81 & 86.2 & 436 & 56.5 \\
\hline Rhode Island & 101 & 37.7 & 27 & 24.1 & 13 & 13.8 & 335 & 43.5 \\
\hline \multicolumn{9}{|l|}{ Infant year of birth } \\
\hline 1969-1978 & 98 & 36.6 & 20 & 17.9 & 14 & 14.9 & 275 & 35.7 \\
\hline 1979-1988 & 88 & 32.8 & 45 & 40.2 & 27 & 28.7 & 290 & 37.6 \\
\hline 1989-1995 & 82 & 30.6 & 47 & 42.0 & 53 & 56.4 & 206 & 26.7 \\
\hline \multicolumn{9}{|l|}{ Infant gender } \\
\hline Male & 131 & 49.4 & 65 & 58.0 & 94 & 100 & 408 & 52.9 \\
\hline Female & 134 & 50.6 & 47 & 42.0 & - & - & 363 & 47.1 \\
\hline Missing & 3 & & & & & & & \\
\hline Maternal age at delivery (mean, sd) & $26.3(6.1)$ & & $27.8(5.3)$ & & $29.3(5.2)$ & & $27.0(5.4)$ & \\
\hline Missing & 3 & & 0 & & 0 & & 0 & \\
\hline Paternal age at delivery (mean, sd) & $29.3(6.3)$ & & $30.8(5.8)$ & & $31.7(6.2)$ & & $29.8(6.1)$ & \\
\hline Missing & 30 & & 11 & & 0 & & 34 & \\
\hline \multicolumn{9}{|l|}{ Maternal race } \\
\hline White & 201 & 90.5 & 94 & 92.2 & 86 & 96.6 & 613 & 90.1 \\
\hline Non-White & 21 & 9.5 & 8 & 7.8 & 3 & 3.4 & 67 & 9.9 \\
\hline Missing & 46 & & 10 & & 5 & & 91 & \\
\hline \multicolumn{9}{|l|}{ Maternal educational level } \\
\hline$<$ High school & 36 & 16.7 & 10 & 9.9 & 7 & 7.9 & 96 & 14.3 \\
\hline High school graduate & 104 & 48.1 & 42 & 41.6 & 26 & 29.2 & 244 & 36.4 \\
\hline Some college & 36 & 16.7 & 32 & 31.7 & 26 & 29.2 & 172 & 25.7 \\
\hline College graduate & 40 & 18.5 & 17 & 16.8 & 30 & 33.7 & 158 & 23.6 \\
\hline Missing & 52 & & 11 & & 5 & & 101 & \\
\hline \multicolumn{9}{|l|}{ Prenatal care began in first trimester } \\
\hline Yes & 162 & 84.4 & 89 & 89.9 & 85 & 97.7 & 473 & 87.9 \\
\hline No & 30 & 15.6 & 10 & 10.1 & 2 & 2.2 & 65 & 12.1 \\
\hline Missing & 76 & & 13 & & 7 & & 233 & \\
\hline \multicolumn{9}{|l|}{ Prenatal cigarette smoking } \\
\hline Yes & 29 & 21.8 & 21 & 31.8 & 12 & 15.6 & 70 & 24.3 \\
\hline No & 104 & 78.2 & 45 & 68.2 & 65 & 84.4 & 218 & 75.7 \\
\hline Missing & 135 & & 46 & & 17 & & & 483 \\
\hline \multicolumn{9}{|c|}{ Prenatal alcoholic beverage consumption } \\
\hline Yes & 19 & 23.8 & 19 & 51.4 & 9 & 29.0 & 69 & 35.6 \\
\hline No & 61 & 76.3 & 18 & 48.6 & 22 & 71.0 & 125 & 64.4 \\
\hline Missing & 188 & & 75 & & 63 & & 577 & \\
\hline \multicolumn{9}{|l|}{ Number of prior livebirths } \\
\hline 0 & 91 & 41.4 & 38 & 37.3 & 43 & 47.8 & 296 & 43.8 \\
\hline 1 & 68 & 30.9 & 36 & 35.3 & 28 & 31.1 & 217 & 32.1 \\
\hline
\end{tabular}


Table 2 Distribution of selected characteristics of cases and controls (Continued)

\begin{tabular}{|c|c|c|c|c|c|c|c|c|}
\hline \multirow[t]{2}{*}{ Characteristic } & \multicolumn{2}{|c|}{ CNS Cases $(N=268)$} & \multicolumn{2}{|c|}{ Oral Clef Cases $(N=112)$} & \multicolumn{2}{|c|}{ Hypospadias Cases $(N=94)$} & \multicolumn{2}{|c|}{ All Controls $(N=771)$} \\
\hline & $n$ & $\%$ & $n$ & $\%$ & $\mathrm{n}$ & $\%$ & $n$ & $\%$ \\
\hline $2+$ & 61 & 27.7 & 28 & 27.5 & 19 & 21.1 & 163 & 24.1 \\
\hline Missing & 48 & & 10 & & 4 & & 95 & \\
\hline \multicolumn{9}{|c|}{ Possible maternal exposure to solvents in workplace ${ }^{a}$} \\
\hline Yes & 2 & 2.5 & 5 & 13.9 & 1 & 3.1 & 4 & 2.1 \\
\hline No & 79 & 97.5 & 31 & 86.1 & 31 & 96.9 & 185 & 97.9 \\
\hline Missing & 187 & & 76 & & 62 & & 582 & \\
\hline
\end{tabular}

${ }^{a}$ Ascertained from a series of questions on jobs and job activities that typically involve solvent exposure (e.g., metal degreasing)

Because we investigated defect diagnoses at birth, it is possible that a differential loss of pregnancies before this point may have led us to underestimate the true effect of PCE exposure. Such a 'competing mortality' bias could exist if the pregnancies most susceptible to PCE-induced birth defects were not included in our study because they were more likely to be spontaneously aborted earlier in pregnancy. Previous findings from our prior research, however, suggest that prenatal PCE exposure is not associated with early pregnancy loss [41].

Numerous animal experiments have found an adverse effect of prenatal exposure to PCE, the closely related solvent trichloroethylene (TCE), and their metabolite trichloroacetic acid (TCA) on the risk of congenital defects. An increased prevalence of cardiovascular, musculoskeletal, central nervous system and ocular anomalies have been observed among chicks and rats over a wide range of prenatal exposure levels (e.g., $[10,11])$.

Many epidemiological studies have also found positive associations between occupational exposure to organic solvents during pregnancy and the risk of congenital anomalies, including oral clefts, neural tube defects and cardiac defects [12-14, 18, 19, 42]. However, these studies are difficult to interpret because broad exposure categories including many different solvents were typically examined. Studies of dry cleaning workers with only PCE exposure were too small to provide meaningful results [43-46].

A smaller body of literature examining women exposed via contaminated air and drinking water has less consistent results with several studies reporting increases in the risk of birth defects associated with PCE and/or TCE exposure [20-26] while others reporting null findings $[24,27,28]$.

Differing results have also been observed for drinking water studies that examined the defects included in our investigation. A 1986 study of well water contaminated with TCE (267 ppb), PCE (21 ppb), and other compounds in Woburn, MA found an increased prevalence of central nervous system, oral cleft and chromosomal defects combined among children with prenatal exposure [23]. While a follow-up study also found that Woburn residents had a higher prevalence of certain defects, including neural tube defects, cleft lip, hypospadias and chonal atresia [27, 47], investigators attributed this to differences in case ascertainment between Woburn and the comparison population [27]. The similar frequency of defects before and after the affected wells were closed also led investigators to conclude that their occurrence was not associated with prenatal exposure to contaminated well water.

In contrast, a 1995 New Jersey study found that PCE drinking water levels $>10 \mathrm{ppb}$ were associated with a 3.5 -fold increased risk of oral clefts (90\% CI: 1.3-8.8), TCE drinking water levels $>5 \mathrm{ppb}$ were associated with a 2.2 fold increased risk of oral clefts (90\% CI: 1.2-4.2), and TCE levels $>10 \mathrm{ppb}$ were associated with a 2.5 -fold increased risk of neural tube defects (90\% CI: 0.9-6.4) [22]. Positive associations were also observed between any prenatal exposure to PCE-contaminated drinking water and the risk of neural tube defects (OR: 3.2, 95\% CI: 0.9-11.0), and oral clefts (OR: 3.0, 95\% CI: 0.7-13.0), and hypospadias (OR: 1.4, 95\% CI: 0.4-5.4) in our previous study of births from Cape Cod MA [20]. Lastly, a study from Marine Corps Base Camp Lejeune found a 2.4-fold increased odds of neural tube defects in relation to TCE exposure levels $>5 \mathrm{ppb}$ (95\% CI: 0.6-9.6) but no associations between neural tube defects and oral clefts and any level of PCE exposure [24].

The two studies using different metrics for airborne solvent exposure also have conflicting results for the defects examined in the present investigation. A study using broadly categorized census-tract estimates of TCE levels reported a 2.0 -fold increased odds of spina bifida for medium exposure levels $\left(0.5-.16 \mu \mathrm{g} / \mathrm{m}^{3}\right)$ (95\% CI: 1.1-3.6) and a 1.3-fold increased odds for high exposure levels $\left(>0.16 \mu \mathrm{g} / \mathrm{m}^{3}\right)(95 \%$ CI: 0.6-2.8) [25] while a study using a highly refined emission weighted residential proximity model found no associations between PCE and TCE and either neural tube defects or oral clefts (PCE ORs and 95\% CI: 0.92, 0.81-1.06 and 0.98, 0.881.08, respectively, and TCE ORs and 95\% CI: 0.95, 0.831.09 and 1.02, 0.92-1.13, respectively) [28].

Possible explanations for differing results among the environmental studies include small numbers of defect cases leading to unstable results, exposure misclassification, inadequate control of confounding, as well as differences in 
Table 3 Frequencies, Odds Ratios and 95\% Confidence Intervals for Birth Defects According to Average Monthly PCE Exposure during Year First Trimester Ended

\begin{tabular}{|c|c|c|c|c|}
\hline & Number of Cases & Number of Controls & Crude Odds Ratio $(95 \% \mathrm{Cl})$ & 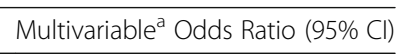 \\
\hline \multicolumn{5}{|c|}{ All Central Nervous System Defects $(N=268)$} \\
\hline Any Exposure & 183 & 523 & $1.0(0.8-1.4)$ & $1.1(0.8-1.6)$ \\
\hline No Exposure & 85 & 248 & 1.0 (-----) & \\
\hline
\end{tabular}

Exposure Categorized by 1980 Action Level

$\begin{array}{lll}>1.136 \mathrm{~g}(>40 \mu \mathrm{g} / \mathrm{L}) & 13 & 32 \\ >0-<=1.136 \mathrm{~g} & 170 & 49 \\ 0 \text { (Referent) } & 85 & 248 \\ P \text { value for trend } & & \end{array}$

$\begin{array}{ll}1.2(0.6-2.4) & 1.2(0.6-2.4) \\ 1.0(0.7-1.4) & 1.1(0.8-1.6) \\ 1.0(-----) & 0.64\end{array}$

All Neural Tube Defects $(N=151)$

Any Exposure $\quad 100 \quad 523$

248

Exposure Categorized by 1980 Action Level

$\begin{array}{lll}>1.136 \mathrm{~g}(>40 \mu \mathrm{g} / \mathrm{L}) & 11 & 32 \\ >0-<=1.136 \mathrm{~g} & 89 & 49\end{array}$

$P$ value for trend

Anencephaly $(N=82)$

$\begin{array}{lll}\text { Any Exposure } & 54 & 523 \\ \text { No Exposure } & 28 & 248\end{array}$

Exposure Categorized by 1980 Action Level

$\begin{array}{lll}>1.136 \mathrm{~g}(>40 \mu \mathrm{g} / \mathrm{L}) & 5 & 32 \\ >0-<=1.136 \mathrm{~g} & 49 & 491 \\ 0 \text { (Referent) } & 28 & 248 \\ P \text { value for trend } & & \end{array}$

Spina bifida with and without hydrocephalus $(N=69)$

$\begin{array}{lll}\text { Any Exposure } & 46 & 523 \\ \text { No Exposure } & 23 & 248\end{array}$

Exposure Categorized by 1980 Action Level

$\begin{array}{lll}>1.136 \mathrm{~g}(>40 \mu \mathrm{g} / \mathrm{L}) & 6 & 32 \\ >0-<=1.136 \mathrm{~g} & 40 & 49 \\ 0 \text { (Referent) } & 23 & 248\end{array}$

$P$ value for trend

Other CNS Defects ( $N=117)$

$\begin{array}{lll}\text { Any Exposure } & 83 & 523 \\ \text { No Exposure } & 34 & 248\end{array}$

Exposure Categorized by 1980 Action Level

$\begin{array}{lll}>1.136 \mathrm{~g}(>40 \mu \mathrm{g} / \mathrm{L}) & 2 & 32 \\ >0-<=1.136 \mathrm{~g} & 81 & 491 \\ 0 \text { (Referent) } & 34 & 248 \\ P \text { value for trend } & & \end{array}$

All Oral Clefts $(N=112)$

$\begin{array}{lll}\text { Any Exposure } & 81 & 523 \\ \text { No Exposure } & 31 & 248\end{array}$

$0.9(0.6-1.3)$

$1.1(0.8-1.7)$

$1.0(-----)$

$1.7(0.8-3.5)$

$1.5(0.7-3.1)$

$0.9(0.6-1.3)$

$1.1(0.7-1.7)$

$1.0(-----)$

0.33

$0.9(0.6-1.5)$

$1.1(0.7-1.9)$

$1.0(-----)$

$1.4(0.5-3.8)$
$0.9(0.5-1.4)$
$1.0(----)$

$1.1(0.4-3.1)$

$1.1(0.6-1.9)$

0.86

$0.9(0.6-1.6)$

$1.2(0.7-2.2)$

1.0 (-----)

$2.0(0.8-5.3)$

$2.0(0.8-5.4)$

$0.9(0.5-1.5)$

$1.1(0.6-2.1)$

1.0 (-----)

0.16

$1.2(0.8-1.8)$

$1.1(0.7-1.8)$

$1.0(-----)$

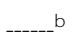

$1.2(0.8-1.8)$

$1.2(0.7-1.9)$

$1.0(----)$

N/A

$1.2(0.8-1.9)$

$1.7(1.0-2.8)$ 
Table 3 Frequencies, Odds Ratios and 95\% Confidence Intervals for Birth Defects According to Average Monthly PCE Exposure during Year First Trimester Ended (Continued)

\begin{tabular}{|c|c|c|c|c|}
\hline & Number of Cases & Number of Controls & Crude Odds Ratio (95\% Cl) & Multivariable ${ }^{a}$ Odds Ratio $(95 \% \mathrm{Cl})$ \\
\hline \multicolumn{5}{|c|}{ Exposure Categorized by 1980 Action Level } \\
\hline$>1.136 \mathrm{~g}(>40 \mu \mathrm{g} / \mathrm{L})$ & 6 & 32 & $1.5(0.6-3.9)$ & $2.2(0.8-6.0)$ \\
\hline$>0-<=1.136 \mathrm{~g}$ & 75 & 491 & $1.2(0.8-1.9)$ & $1.7(1.0-2.8)$ \\
\hline 0 (Referent) & 31 & 248 & $1.0(------)$ & \\
\hline$P$ value for trend & & & & 0.13 \\
\hline \multicolumn{5}{|c|}{ Cleft Lip with or without Cleft Palate $(N=59)$} \\
\hline Any Exposure & 44 & 523 & $1.4(0.8-2.5)$ & $2.1(1.1-4.0$ \\
\hline No Exposure & 15 & 248 & $1.0(------)$ & \\
\hline \multicolumn{5}{|c|}{ Exposure Categorized by 1980 Action Level } \\
\hline$>1.136 \mathrm{~g}(>40 \mu \mathrm{g} / \mathrm{L})$ & 5 & 32 & $2.6(0.9-7.6)$ & $3.8(1.2-12.3)$ \\
\hline$>0-<=1.136 \mathrm{~g}$ & 39 & 491 & $1.3(0.7-2.4)$ & $1.9(1.0-3.8)$ \\
\hline 0 (Referent) & 15 & 248 & $1.0(------)$ & \\
\hline$P$ value for trend & & & & 0.02 \\
\hline \multicolumn{5}{|l|}{ Cleft Palate Alone $(N=53)$} \\
\hline Any Exposure & 37 & 523 & $1.1(0.6-2.0)$ & $1.4(0.7-2.7)$ \\
\hline No Exposure & 16 & 248 & $1.0(-----)$ & \\
\hline \multicolumn{5}{|c|}{ Exposure Categorized by 1980 Action Level } \\
\hline$>1.136 \mathrm{~g}(>40 \mu \mathrm{g} / \mathrm{L})$ & 1 & 32 & $----{ }^{b}$ & $-\mathbf{- - - -}^{\mathrm{b}}$ \\
\hline$>0-<=1.136 \mathrm{~g}$ & 36 & 491 & $1.1(0.6-2.1)$ & $1.4(0.7-2.8)$ \\
\hline 0 (Referent) & 16 & 248 & $1.0(------)$ & \\
\hline$P$ value for trend & & & & N/A \\
\hline \multicolumn{5}{|l|}{ Hypospadias $(N=94)^{c}$} \\
\hline Any Exposure & 58 & 266 & $0.9(0.5-1.4)$ & $1.3(0.8-2.2)$ \\
\hline No Exposure & 36 & 142 & $1.0(------)$ & \\
\hline \multicolumn{5}{|c|}{ Exposure Categorized by 1980 Action Level } \\
\hline$>1.136 \mathrm{~g}(>40 \mu \mathrm{g} / \mathrm{L})$ & 3 & 11 & $1.1(0.3-4.1)$ & $2.1(0.5-8.3)$ \\
\hline$>0-<=1.136 \mathrm{~g}$ & 55 & 255 & $0.9(0.5-1.4)$ & $1.3(0.8-2.2)$ \\
\hline 0 (Referent) & 36 & 142 & $1.0(------)$ & \\
\hline$P$ value for trend & & & & 0.31 \\
\hline
\end{tabular}

${ }^{a}$ All adjusted analyses control for state of birth, delivery year. In addition, maternal alcohol use during pregnancy is controlled in the oral cleft analysis and maternal race is controlled in the hypospadias analysis

${ }^{\mathrm{b}}$ Not calculated

${ }^{c}$ Analysis includes only male cases and controls

N/A not applicable

exposure assessment methods and exposure levels. In particular, it is possible that the stronger associations observed in our prior cohort study in Cape Cod MA resulted from higher exposure levels. The average monthly exposure levels in our prior cohort study ranged from $9.6 \times 10^{-05}$ to $131.8 \mathrm{~g}$ and the 25th, 50th, 75th and 90th percentiles were $0.1,0.6,2.3$ and $6.4 \mathrm{~g}$, respectively [20]; see Table 1 for comparison.

In summary, the results of the present study suggest that pregnant women with "high" levels of exposure to PCE-contaminated drinking water $(>40 \mu \mathrm{g} / \mathrm{L})$ have increased odds of having a child with spina bifida, cleft lip and hypospadias. These findings are biologically plausible given evidence of placental transfer of PCE [48]. They also support the results of several other studies that have observed increased risks of certain birth defects following prenatal exposure to solvents in occupational and environmental settings. Even though PCE contamination from VLAC pipes was remediated many years ago and the levels are no longer elevated in MA and RI [7, 8], the solvent remains a common contaminant of U.S. drinking water supplies [1] and so environmental regulations must be guided by a precautionary perspective that safeguards pregnant women and their offspring. 


\section{Abbreviations}

Cl: Confidence Interval; GIS: Geographic Information System; MA: Massachusetts; OR: Odds Ratio; PCE: Tetrachloroethylene; RI: Rhode Island; SNARL: Suggested no adverse response action level; TCE: Trichloroethylene; VLAC: Vinyl-lined asbestos-cement

\section{Acknowledgements}

The authors would like to acknowledge assistance of the women who took the time to respond to the study questionnaire and local water companies in Massachusetts and Rhode Island and the Massachusetts Department of Environmental Protection who provided historical information on the VLAC pipes. The authors would also like to acknowledge study staff members Shane Hennessey and Winnie $\mathrm{Ng}$ for their assistance in computerizing the water system data and geocoding the subject's residential addresses.

\section{Funding}

This work was supported by the National Institute of Environmental Health Sciences Superfund Research Program 5P42ES007381.

\section{Availability of data and materials}

The datasets generated and analyzed during this study are not publically available due to IRB restrictions. Non-identifiable data are however available from the authors upon reasonable request and with permission from the IRBs at Boston University, Massachusetts Department of Public Health, and Rhode Island Department of Health.

\section{Authors' contributions}

AA conceived the study, oversaw its coordination, directed the analysis, and drafted the initial manuscript. LG helped oversee the study, directed the geocoding, completed the exposure assessments and assisted in the analysis and manuscript preparation. MW helped oversee the study, conducted the data analyses and assisted in manuscript preparation. LB identified and traced the study subjects, obtained VLAC pipe information for study towns outside of Cape Cod MA and assisted in the analysis and manuscript preparation. PF and W provided technical input to study design, analysis, and manuscript preparation. All authors read and approved the final manuscript.

\section{Ethics approval and consent to participate}

This research was approved by the Institutional Review Boards (IRB) of Boston University Medical Center ( $\mathrm{H}-31740)$, the Massachusetts Department of Public Health (347795-11) and the Rhode Island Department of Health (2014-08). In addition, all subjects gave their consent to participate.

\section{Consent for publication}

Not applicable.

\section{Competing interests}

The authors declare that they have no competing interests.

\section{Publisher's Note}

Springer Nature remains neutral with regard to jurisdictional claims in published maps and institutional affiliations.

\section{Author details}

${ }^{1}$ Department of Epidemiology, Boston University School of Public Health, 715 Albany Street, Talbot 3 East, Boston, MA 02118, USA. Biostatistics and Epidemiology Data Analytics Center, Boston University School of Public Health, 715 Albany Street, Fuller-9, Boston, MA 02118, USA. ${ }^{3}$ Department of Environmental Health, Boston University School of Public Health, 715 Albany Street, Talbot 4 West, Boston, MA 02118, USA. ${ }^{4}$ University of California, Irvine, Program in Public Health, 653 East Peltason Drive, Irvine, CA 92697, USA.

Received: 20 July 2018 Accepted: 24 October 2018

Published online: 06 November 2018

\section{References}

1. US Environmental Protection Agency. Toxicological review of tetrachloroethylene (perchloroethylene). Washington: US Environmental Protection Agency; 2012
2. Moran MJ, Zogorski JS, Squillance PJ. Chlorinated solvents in groundwater of the United States. Environ Sci Technol. 2007:41:74-81.

3. Focazio MJ, Kolpin DW, Barnes KK, Furlong ET, Meyer MT, Zaugg SD, et al. A national reconnaissance for pharmaceuticals and other organic wastewater contaminants in the United States - II) untreated drinking water sources. Sci Total Environ 2008:402: 201-216.

4. Larson CD, Love T, Reynolds G. Tetrachloroethylene leached from lined asbestos-cement pipe into drinking water. JAWWA. 1983;75:184-90.

5. Demond $\mathrm{AH}$. A Source of Tetrachloroethylene in the drinking water of New England: an evaluation of toxicity of Tetrachloroethylene and the prediction of its leaching rates from vinyl-lined Asbestos-cement pipe. Massachusetts Institute of Technology. 1982.

6. State of Rhode Island and Providence Plantations. Inter-Office Memo: Asbestos cement (a.C.) vinyl-lined pipe preliminary survey for tetrachloroethylene determination. 1980.

7. Massachusetts Department of Environ Prot Tetrachloroethylene Sampling Results. 2013.

8. Rhode Island Department of Health. Center for Drinking Water Quality. In: 2016 Annual Report. Providence: Rhode Island Department of Health; 2016. http://www.health.ri.gov/publications/annualreports/ 2016DrinkingWaterQualityCompliance.pdf. Accessed 28 May 2018.

9. International Agency for Research on Cancer. IARC Monogr Eval Carcinog Risks Hum. In: Some chlorinated solvents and their Meta, vol. 106. Lyon: IARC; 2014.

10. Saillenfant AM, Langonne I, Sabate JP. Developmental toxicity of trichloroethylene, tetrachloroethylene and four of their metabolites in rat whole embryo culture. Arch Toxicol. 1995;70:71-82.

11. Johnson PD, Dawson BV, Goldberg SJ. Cardiac teratogenicity of trichloroethylene metabolites. J Am Coll Cardiol. 1998;32:540-5.

12. Laumon B, Martin JL, Bertucat I, Verney MP, Robert E. Exposure to organic solvents during pregnancy and oral clefts: a case-control study. Repro Toxicol. 1996:10:15-9.

13. Brender J, Suarez L, Hendricks K, Baetz RA, Larsen R. Parental occupation and neural tube defect-affected pregnancies among Mexican Americans. J Occup Environ Med. 2002;44:650-6

14. Chevrier C, Dananché B, Bahuau M, Nelva A, Herman C, Francannet C. Occupational exposure to organic solvent mixtures during pregnancy and the risk of non-syndromic oral clefts. Occup Environ Med. 2006;63:617-23.

15. Gilboa SM, Desrosiers TA, Lawson C, Lupo PJ, Riehle-Colarusso TJ, Stewart PA, et al. Association between maternal occupational exposure to organic solvents and congenital heart defects, National Birth Defects Prevention Study, 1997-2002. Occup Environ Med. 2012;69:628-35.

16. Garlantézec R, Monfort C, Rouget F, Cordier S. Maternal occupational exposure to solvents and congenital malformations: a prospective study in the general population. Occup Environ Med. 2009;66:456-63.

17. Cordier S, Garlantezec R, Labat L, Rouget F, Monfort C, Bonvallot N, et al. Exposure during pregnancy to glycol ethers and chlorinated solvents and the risk of congenital malformations. Epidemiol. 2012;23:806-12.

18. Desrosiers TA, Lawson CC, Meyer RE, Richardson DB, Daniels JL, Waters MA, et al. Maternal occupational exposure to organic solvents during early pregnancy and risks of neural tube defects and orofacial clefts. Occup Environ Med. 2012;69:493-9.

19. Hao Y, Tian S, Jiao X, Mi N, Zhang B, Song T, et al. Association of Parental Environmental Exposures and Supplementation Intake with risk of Nonsyndromic Orofacial clefts: a case-control study in Heilongjiang Province, China. Nutrients. 2015;20:7172-84

20. Aschengrau A, Janulewicz P, Weinberg J, Gallagher L, Winter M, Vieira V, et al. Prenatal exposure to Tetrachloroethylene-contaminated drinking water and the risk of congenital anomalies: a retrospective cohort study. Environ Health. 2009;8:44.

21. Goldberg SJ, Lebowitz MD, Graver EJ, Hicks S. An association of human congenital cardiac malformations and drinking water contaminants. J Am Coll Cardiol. 1990;16:155-64.

22. Bove FJ, Fulcomer MC, Klotz JB, Esmart J, Dufficy EM, Savrin JE. Public drinking water contamination and birth outcomes. Am J Epidemiol. 1995;141:850-62.

23. Lagakos SW, Wessen BJ, Zelen M. An analysis of contaminated well water and health effects in Woburn, Massachusetts. J Am Stat Assoc. 1986;81:583-96.

24. Ruckart PZ, Bove FJ, Maslia M. Evaluation of exposure to contaminated drinking water and specific birth defects and childhood cancers at marine Corps Base camp Lejeune, North Carolina: a case-control study. Environ Health. 2013;12:104. 
25. Swartz MD, Cai Y, Chan W, Symanski E, Mitchell LE, Danysh HE, et al. Air toxics and birth defects: a Bayesian hierarchical approach to evaluate multiple pollutants and spina bifida. Environ Health. 2015;14:16.

26. Forand SP, Lewis-Michl EL, Gomez Ml. Adverse birth outcomes and maternal exposure to trichloroethylene and tetrachloroethylene through soil vapor intrusion in New York state. Environ Health Perspect. 2012;120: 616-21.

27. Massachusetts Department of Public Health. Centers for Disease Control and Prevention, Massachusetts Health Research Institute. In: Final report of the Woburn environmental and birth study. Cambridge: Massachusetts department of Public Health; 1996.

28. Brender JD, Shinde MU, Zhan FB, Gong X, Langlois PH. Maternal residential proximity to chlorinated solvent emissions and birth defects in offspring: a case-control study. Environ Health. 2014;13:96.

29. Adams MM, Greenberg F, Khoury MJ, Marks JS, Oakley GPJ. Trends in clinical characteristics of infants with spina bifida -Atlanta, 1972-1979. Am J Dis Child. 1985;139:514-7.

30. Limb CJ, Holmes LB. Anencephaly: changes in prenatal detection and birth status, 1972 through 1990. Am J Obstet Gynecol. 1994;170:1333-8.

31. Webler T, Brown HS. Exposure to tetrachloroethylene via contaminated drinking water pipes in Massachusetts: a predictive model. Arch Environ Health. 1993:48:293-7.

32. Aschengrau A, Ozonoff D, Paulu C, Coogan P, Vezina R, Heeren T, et al Cancer risk and Tetrachloroethyene-contaminated drinking water in Massachusetts. Arch Environ Health. 1993;48:284-92.

33. U.S. Environmental Protection Agency. EPANET 2.0. https://www.epa.gov/ water-research/epanet. Accessed 28 May 2018.

34. Aral MM, Maslia ML, Ulirsch GV, Reyes JJ. Estimating exposure to volatile organic compounds from municipal water-supply systems: use of a better computational model. Arch Environ Health. 1996;51:300-9.

35. Sadler TW. Langman's medical embryology. 13th ed. Philadelphia: Wolters Kluwer Health; 2015. p. 126-40.

36. Gallagher LG, Vieira VM, Ozonoff D, Webster TF, Aschengrau A. Risk of breast cancer following exposure to tetrachloroethylene-contaminated drinking water in Cape Cod, Massachusetts: reanalysis using a modified exposure assessment. Environ Health. 2011;10:47.

37. Massachusetts Department of Public Health. Bureau of Family and Community Health. Massachusetts Birth Defects 2000-2001, 2005.

38. Rhode Island Department of Health. Rhode Island Birth Defects Data Book 2016.

39. Ackerman J. Pipes pollute some N.E water Boston Globe, 1980.

40. Rothman KJ, Greenland S, Lash TL. Modern Epidemiology. 3rd ed. Philadephia: Lippincott, Williams and Wilkins; 2008. p. pp219.

41. Aschengrau A, Weinberg J, Gallagher L, Winter M, Vieira V, Webster T, et al. Prenatal exposure to Tetrachloroethylene-contaminated drinking water and the risk of pregnancy loss. Water Qual Expo Health. 2009;1:23-34.

42. Lorente C, Cordier S, Bergeret A, De Walle HEK, Goujard J, Ayme S, et al. Maternal occupational risk factors for oral clefts. Scand J Work Environ Health. 2000;26:137-45.

43. Kyyronen $\mathrm{P}$, Taskinen $\mathrm{H}$, Lindbohm ML, Hemminki K, Heinonen OP. Spontaneous abortions and congenital malformations among women exposed to tetrachloroethylene in dry cleaning. J Epidemiol Comm Health. 1989:43:346-51.

44. Bosco MG, Talamanca-Figa I, Salerno S. Health and reproductive status of female workers in dry cleaning shops. Int Arch Occup Environ Health. 1987; 59:295-301.

45. Olsen J, Hemminki K, Ahlborg G, Bjerkedal T, Kyyronen P, Taskinen H, et al. Low birth weight, congenital malformations, and spontaneous abortion among dry-cleaning workers in Scandinavia. Scand J Work Environ Health. 1990;16:163-8

46. Ahlborg G. Pregnancy outcome among women working in laundries and dry-cleaning shops using tetrachloroethylene. Am J Indust Med. 1990;17: 567-75.

47. Bove F, Shim Y, Zeitz P. Drinking water contaminants and adverse pregnancy outcomes: a review. Environ Health Perspect. 2002;110:61-74.

48. Ghantous H, Danielsson BRG, Dencker L, Gorczak J, Vesterberg O. Trichloroacetic acid accumulates in murine amniotic fluid after tri- and tetrachloroethylene inhalation. Acta Pharmacol et Toxicol. 1986:58:105-14.

\section{Ready to submit your research? Choose BMC and benefit from}

- fast, convenient online submission

- thorough peer review by experienced researchers in your field

- rapid publication on acceptance

- support for research data, including large and complex data types

- gold Open Access which fosters wider collaboration and increased citations

- maximum visibility for your research: over $100 \mathrm{M}$ website views per year

At BMC, research is always in progress.

Learn more biomedcentral.com/submissions 